\title{
Examining the influence of student's perception on mathematics performance: Case of three selected Rwandan secondary schools
}

\author{
Kabeera, Pontian $\bowtie$ \\ Beijing Normal University, China (pontiankbr@outlook.com)
}

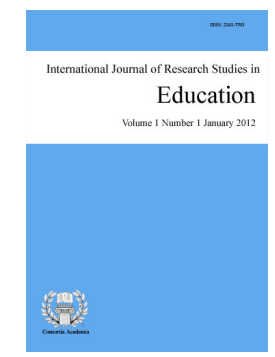

ISSN: 2243-7703 Online ISSN: 2243-7711

Received: 20 February 2018

Revised: 18 March 2018 DOI: $10.5861 /$ ijrse. 2018.3007

Accepted: 10 April 2018

OPEN ACCESS

\section{Abstract}

Over the years, mathematics has continued to prove an impeccable subject to all students throughout the world. These difficulties have therefore prompted many students to drop the course and opt for the courses considered to be much easier and which students feel they can pass. Therefore the study examines the factors that influences student's perceptions towards mathematics and was carried out in three selected Rwandan secondary schools. The study took a qualitative case design and it explored the perceptions of high school students towards mathematics in three secondary schools in Rwanda. It further analyzed relationship between the teachers and the students and how this relationship can positively or negatively influence the student's perceptions towards the general mathematics performance. The research revealed that Language is one of the factors that have influenced the students' perceptions towards mathematics. It was equally exposed that age greatly influences the way students view mathematics, it highlighted that students from the age of 14-18 usually view mathematics as a hard subject. The study found out that there was a significant discrepancy in perceptions between the ways girls perceive mathematics to boys. The research's results show that there is a grand relationship between teachers, learning materials, and school administrators' supports on the self-confidence of students of all ages, gender, beliefs, and attitudes, and thus influence positive attitudes towards mathematics. The study also revealed that gender related factors influence the student's perceptions towards mathematics, it noted that girls tend to develop a low self-esteem that they cannot out compete boys in mathematics.

Keywords: perception; students; mathematics 


\section{Examining the influence of student's perception on mathematics performance: Case of three selected Rwandan secondary schools}

\section{Introduction}

Perceptions towards mathematics are vital towards the effective facilitation of learning and teaching the discipline. This concept influences the instruction of mathematics both positively and negatively, the school system, family background and student's attitudes towards the school altogether have an effect on the way students view mathematics. Barton (2000) and Furinghetti and Pekhen (2002) remarks that the way mathematics is taught in the classroom and perceived by the students makes the teachers believe whether they are actually presenting it in a valid and dependent way that does not disaffect loads of students from pursuing it at higher levels of learning.

Several researchers have indicated that student's positive discernment towards mathematics can steer many into mathematic success. Therefore an approach to get better of the students attitude towards mathematics at a young age would present the opportunity for many students to perform well in mathematics while at a higher level of education. Perceptions and beliefs about mathematics lays heredity in the people's lived and past experiences which comprises both cognitive and affective dimensions (Rensaa, 2006). Cognitively, it relates to a person's understanding or knowledge and credence's in addition to other cognitive demonstrations while affective domain refers to a person's to attitudes, feelings and emotions about mathematics.

The term is also unstated broadly to embrace all visual and spoken representations, metaphorical images, associations and beliefs, attitudes and feelings towards learning of mathematics. Therefore the ultimate aim of this study is to examine, explore, identify and analyze a range of student's perceptions, beliefs and attitudes that influences their take on mathematics in secondary school. It is extensively said that student's unenthusiastic perceptions and myths towards mathematics are very broad mainly in the developed economies (Mtetwa \& Garofalo, 1989; Ernest, 1996; Gadanidis, 2012). Sam (2002) argues that many students are petrified of mathematics and feel powerless in the presence of mathematical ideas.

They consider Mathematics as unbearably a "difficult, frosty and abstract subject whereby in some cultures, It is mostly a male dominated discipline" (Ernest, 1996, p. 802). Buxton, cited by Sam (2002) viewed mathematics as "fixed, absolute, external, intractable and uncreative" or "a timed-test"(p. 115). That evens those whose professions call for deeper understanding of mathematics "often quay or manifest an image that mathematics is well-stocked stockroom from which to select ready-to-use formulae, theorems, and results to advance their own theories"(Peterson, 1996).

Several academics have attempted to make clear of this phenomenon through the widespread beliefs on mathematical myths highlighting that "studying mathematics is a question more of ability than effort"(McLeod, 1992, p. 575) or some people are born with those natural abilities for mathematics". Many people especially student's believe that it is only academically gifted mates that can be powerful in the presence of mathematics or those who 'inherited mathematical ability'. While other widely held belief is that mathematics is a male dominant subject justifying the fact that boys do better in mathematics those girls (Ernest, 1995). While others hold the view that the general challenges in mathematics performance is as a result of the permanent state over which they have no or little control.

McLeod (1992) argues that, the role of parents towards the child's better mathematical performance should not be underestimated. Parents play a primary role towards building students beliefs and attitudes mathematics and thus better performance. Sam (2002) parents' take on mathematics greatly communicates sense of the subject to the child and greatly influences the way it is facilitated thus arousing the interest of the children to 
Examining the influence of student's perception on mathematics performance: Case of three Rwandan schools pursue it with a good attitudes and results into better performance in the long run.

\section{Background}

Mathematical concepts as forms of teaching and learning have been in existing for many years, dated 5000 years ago. It is believed that the notion of mathematics as a discipline was invented at the time when reading and writing was being inaugurated by the Sumerians. From then to this day, mathematics has since become a dominant discipline among world academics with all education institutions throughout the world prioritizing it in their education curriculum. Throughout the world, mathematics is viewed as one of the fundamental intellectual tools that every educated individual should have. History tells us that, many years ago, humans faced the challenge of measuring and communicating about time, quantity as well as measuring the distance and there was need to find the solution to such a pressing issues at the time. Thus, the renaissance of mathematics as an ultimate discipline that should be upheld in its highest regard when it comes to addressing those challenges.

The world today looks at mathematics as an engine for the development of all scientific disciplines. It is indirectly used in all facets of life. Mathematics plays a key position when it comes to determining how individuals deal with the various spheres of private, social, and civil life (Anthony \& Walshaw, 2009). This explains why most institutions in the world pressurize the students to study mathematics both at basic and secondary education. On that accord therefore, Mathematics is considered as a central subject in all ordinary levels of education in Rwanda. It is however deplorable that many of the modern students writhe with mathematics with atrociously low performance in the final examinations.

In Rwanda for example, the general student's performance in mathematics in Ordinary level has been encouraging given the energy and emphasis put in it as opposed to other humanity subjects. Students seem to demonstrate pitiable consideration of Mathematical concepts and are therefore not equipped enough to form the fitting Mathematical models that can be addressed with the requisite skills. It has also been realized that many students have developed negative attitude towards the study of Mathematics as a result of mass failure of students of the subject. It is an irrefutable fact that the successfulness of learning the subject is contingent on myriad of factors. School, classroom, student and teacher factors all impinge on the learning of Mathematics. In particular, the seriousness or otherwise attached to the teaching of Mathematics invariably affects students' performance in their final examinations.

\section{Review of Literature and Theoretical Framework}

It is not for the faints of hearts to come up with a well-developed theoretical framework when studying beliefs and attitudes and it has been equally a trek on the sea to develop any coherent framework in the area of people's believes and their attitudes to many researchers and none has to this day managed to claim any success . According to Hannula (2004) there has been numerous debates going on about the appropriate theoretical frameworks that can be used while conceptualizing the effects of mathematics in education.

Presently there is no defined and collective lingo for describing the affective domain, within a theoretical framework that gives consents for its systematic study. Hence, the study is guided by the variety of concepts and thrashes out linkage between their conceptions. Beliefs and attitudes as well as perspectives and opinions cannot directly be observed and have to be contingent, and because of their closeness it is quite tricky to have a common definition of these notions (Leder \& Forgasz, 2002). Researchers have therefore come up to isolate the concepts that have no satisfactory results. Kislenko et al. (2005) explained the interplay among thinking, feeling, opinions, beliefs, views and perspectives. Scholars argue that beliefs are a part of persons' understanding that is vastly subjective and on the other hand the conceptions of feelings and beliefs are often overlapping and cannot distinguished.

Some researchers consider beliefs to be part of knowledge (Furinghetti, 2003; Renzi, 2005, Brown, 2006), some scholars think beliefs are part of attitudes (Pehkonen \& Pietilä, 2004), and some consider them as part of 
conceptions (Thompson, 1992). Researchers such as Gnacio et al. (2006) used mathematics self-concept to refer to people's beliefs relating to the world of mathematics, it explores what the person has managed to learn in the course of program, it brings together a person's ideas and beliefs, attitudes and judgments. It is important to note that an individual's perceptions affect his desires and love towards mathematics and hence deconcetration while learning it which in the end brings about horrendous results to both the students and the institutions.

Hannula (2006) pointed out that a having a phobia with mathematics by the learner is within his or her structure of believes. In this case therefore beliefs are vehicles of conveniences through which manages to construe the world (Philipp, 2006). Research has showed beyond reasonable doubt that the attitudes that the aged people or adults experienced as learners is under normal circumstances carried forward in their adult life and these feelings are important factors in the ways they relate to the young generations of learners. There is the general short of interest and a slightly higher tendency of mathematics evading amongst students in many countries in the world. Many learners hold the view that to be good in mathematics is not actually due to the efforts but rather the ability (McLeod, 1992). Hence many students taking this general poor performance in mathematics as a permanent state over which they have little control.

Tobias (2003) advances that many aged people have been deprived of many professional and personal opportunities because of their poor performance in mathematics and therefore to many, these negative experiences remain and keep haunting them throughout their lives. Moscucci (2008) tables the idea of “ameta-belief systems activity' on the grounds of learning experimentations, with the main notion of making it obvious for the learners to be aware of all the necessary requirements for them to be able to perform better in mathematics. Many teacher's beliefs and views seem to originate in and be shaped by experiences" (cited from Thompson, 1992, p. 139). While Pajares explains that much as beliefs which are formed from experiences appear to be more resistant, it is imperative to note that learning and inquiries entirely depends on the an individual prior beliefs.

For this case therefore there is a fundamental need for teachers to learn about the students from the perspective of the students themselves. This will help teachers to prepare relevant content that will improve the general students' academic performance. A deeper analysis into the perceptions of the learners with a stare on their mathematical familiarity can prove a landmark in developing effective pedagogy for improved mathematics achievement. While analyzing the Educational Effectiveness Research (EER) which placed its major focus on determining how classes and schools are linked with variation in student outcomes. The recent study analyzed the academic outcome as reflected in the way students pass the exams.

Looking at the past studies by school effectiveness according to Coleman et al. (1966) they asserted that school-level factors does not in any way affect student's mathematics achievements as compared to the students main making following studies by the scholars (Creemers \& Kyriakides, 2008; Ma \& Klinger, 2000; Mohammad, 2012; Opdenakker et al., 2002; Rumberger \& Palardy, 2004; Scheerens \& Bosker, 1997) highlighted that the school plays a role in the students poor performance in mathematics but the students perception and attitude towards mathematics contributes a lot towards their poor performance.

\subsection{Objectives of the Study}

The study is guided by three fundamental objectives such as identifying an array of student's perceptions towards mathematics held by Rwanda students from the three selected schools. To examine the factors that influences students perceptions constructs and their general mathematics performance. To explore the cause of students poor performance in mathematics in Rwandan schools

\subsection{Significance of the study}

When you talk of mathematics to many school going children, you certainly going to get exposed to the worst response, as a subject, there is always mixed reaction from the students across all sections. One of the most 
pressing challenges that teachers of mathematics faces to this day is to make students look at mathematics positively as a subject like any like any other and once given time, they can perform well. In this case, teachers ought to know student's effective beliefs and inter-relations with those learning mathematics so that they can employ more effective strategies in teaching mathematics hence improving their performance in the subject and end their negativity in it. This study is therefore aimed at finding out the difficulties that students face while studying mathematics. It will explore the students affective reasons for not liking the subject and to know how their motivational characters help some especially those who actually the subject.

We need to understand that mathematics as a discipline affects all the facets of human life at all levels. It is considered by all societies as the beacon of scientific knowledge and progress to and knowledge that is crucial in social- economic development of a nation. It in the regards of mathematics that made Eraikhuemen (2003) to hypothesize that a disciplined and ordered pattern of life can only be achieved through the culture of mathematics. It is however sad to note that, students' achievement in this important subject over the years has not been encouraging at the all most levels of education in Rwanda. Therefore taking the chance to examine the different beliefs and perceptions plus images and other related myths that has continued to haunt student's interests in pursuing such a noble course, there is a budding for such mischievous beliefs and attitudes can be fully challenged, promoted and discouraged and then appropriate information is obtained to promote and students positive attitude and understanding towards mathematics and other scientific related fields. The results of this study might inform the extent of the influences of parents and teachers in shaping students' perceptions of mathematics.

Well the information obtained is to purely bring about a positive attitude towards mathematics among the students. The study will help is to understand other actors that have influenced the students bad attitude towards mathematics and how such actors can better understand their roles in shaping the students images towards mathematics. Understanding the students take towards mathematics learning experience in school and this can their perceptions towards the subject helps to understand the best approaches that can be used to better the teaching of the subject in the years. The results from the study equally bring about new knowledge which may also help to enhance better curriculum planning and teacher development programs.

Students' views of mathematics are important as they can shape the way in which they learn mathematics. Such views and perceptions may have more influence than knowledge in determining how individuals organize and define tasks. Perceptions of what mathematics is and is not, may affect attitudes, performance, confidence and perceived usefulness of mathematics. The study will therefore contribute tremendously in the way mathematics teachers conduct their classes to be able to win back students love towards mathematics. It will also add to the already existing studies on students perceptions towards mathematics and ensure that their general perception and performance towards mathematics hikes vastly. Parent's role towards their children general studies will be highlighted and they will be able to take a lead in the learning process of their children.

\subsection{Methodology}

Using a qualitative research method, this research explored the perceptions of high school students towards mathematics in three secondary schools in Rwanda. The unit of analysis is the process, meaning the research further analyzed relationship between the teachers and the students and how this relationship can positively or negatively influence the student's perceptions towards the general mathematics performance. A case study was mostly suitable simply because the precincts between the students and the teachers was well demarcated (Yin, 2003). In addition to that, this qualitative method allowed me to focus principally on the student's perception towards mathematics.

My sample size was 30 comprising of students from three selected schools and 6 mathematics teachers. The students were interviewed in their respective focused group each consisting of 8 students Besides that, I also got more data after reading other related documents and other scholarly work on student's perceptions towards 
mathematics.

The study was motivated by three research questions: what is the general perception of students towards mathematics? What is the student's general performance in mathematics? What are the factors that influence the student's performance in mathematics?

In order to achieve reliability and validity of my data, most of these responses were similar in one way or others in terms of boys responses and girls responses on the perception of mathematics and the teachers responses were also similar about the factors the influences students perception. After the interviewing the students and teachers the data transcription was taken back to the respondents to cross check and confirm the accuracy of their responses before data analysis.

\section{Findings and Discussions}

It should be noted that the reason behind the study was to examine the individual student's perceptions and what influences their perceptions towards their general performance in mathematics. In this regard, many aspects were highly envisioned ranging from demographic factors, gender, and age and domicile language. There was also a hypothesis that boys perceive mathematics more positive those girls in schools. The study found out that there was a significant discrepancy in perceptions between the ways girls perceive mathematics to boys. This is trusty given the findings by Hoang (2008) who highlighted that male students have consistently showed more love towards mathematics than girls students though Mohamed and Waheed (2011) tries to challenge Hoang by showing in their survey that students perceptions towards mathematics is medium and that there is no gender difference in their attitudes.

Forgasz and Murimo (2011) advances that students perceptions towards mathematics lays heredity in gender related issues where boys perceive mathematics with positivity as opposed to girls and thus influencing their general performance in mathematics. While, Isiksal and Cakiroghi (2010) like many other scholars notes that considering the general performance of students in mathematics, boys have over the years passed it better than girls hence the yard stick for their positive attitude towards mathematics than girls. Other studies have showed that girls have lower Self-esteem than boys (Kleinfeld, 2006). Female students usually fail mathematics and hence developing a negative perception simply because of the low self-esteem which is actually different with male students who instead gain poise as they grow older while girls lose the vivacity and sense of self they displayed in the lower grades.

The study also looked at the aspect of age and Perceptions and found out that, two variables also brought about the discrepancies in the way mathematics is perceived by the students. By using descriptive statistics, it clearly indicated that 14-18 year old school going children have a different perception towards mathematics than the much older students. These findings were consistent with what Martinot and Désert (2007) advances, they found out that age is not actually statistically significant when comes to elucidating student's levels of perception towards mathematics at different age groups.

Language and Perceptions of Mathematics was also highly explored to find out whether it has an impact towards to the way students perceive mathematics. It was noted that there was a significance difference in the way students perceive mathematics across different language groups. While Analysis discrepancies therein, it was confirmed that language factors plays no or less part in influencing the students perceptions or attitudes towards mathematics. we need to understand that Rwanda is a Multi-lingual society and cultural societies with many students and teaches coming from all the cohorts but even then students from those different background again perceive mathematics differently which either impedes or hike their desires in the subject hence performing well or vice- versa.

For students to effectively learn, they need a system and clear lingual to communicate through all the mathematical concepts. Nordin (2005) put it that Language is primary when it comes to swaying student's thoughts 
Examining the influence of student's perception on mathematics performance: Case of three Rwandan schools

by molding perceptions and structuring ideas. For that matter, therefore, this could be termed as general lack of the aptitude to comprehend the subject matter and probably the language of instruction. For many years there has been several studies in this very discipline, but the effects of languages and students perceptions of mathematics have been widely results are inconsistent, with a variety of researches and studies highlighting that the knowledge and skills are new, unfamiliar and different from the language used in everyday life (Marissa, 2009). However with an introspective look, this may give birth to other problems hence worsening the general understanding of the mathematics concepts. Many of the researchers have advocated for more emphasis in building students proficiency in English which is the means of instruction before they could learn mathematics such they are able to comprehend mathematical notions.

Looking at the student's perceptions and teachers take on the matter, the research's results indicated that there is a grand bond between teachers, learning materials and schools administration supports self-confidence of the learners of all ages and sex, beliefs and attitudes and thus influence positive attitudes towards mathematics. It is from this analysis, that one affirms that, teacher's learning materials which include language of instructions, family background and support, myth attached to the subject and the tricky part of it predicts the performance of mathematics.

\section{Conclusion and Implications}

The study looked at series of student's perception build or constructs towards mathematics performance and it was carried-out from three Rwandan secondary schools. The results from the study highlighted seven factors that influence student's perception towards mathematics. There were factors such as inability to comprehend mathematical concepts, teachers', teacher's inability to prepare fitting or relevant materials for learning, the issues of family background, low self-esteem or self-confidence were some the pressing factors that influences such perceptions. Gender related factors were highly noted by the respondents as a serious factor that influences the way students view mathematics. Many look at mathematics as a subject for male students making the female students look as if they cannot handle mathematics at all this in the long affect their general mathematics performance hence poor school performance. It was equally exposed that age greatly influences the way students view mathematics, it highlighted that students from the age of 14-18 usually view mathematics as a hard subject. The research further revealed language related factors significantly affect the way students perform in mathematics advocated that prior introduction English proficiency before the actual classes is crucial for changing this early negative attachment to mathematics.

The study further showed that for all the students with a strong drive for academic success and more-so in mathematics and those who believe that their efforts would lead them to good performance hence enhancing their academic achievements, many times pass mathematics regardless of the gender and sex. On that accord therefore the research's recommendations for this particular subject is that parents and teachers must be at the helm towards playing a momentous role in shaping children and students' perceptions as well as attitudes towards mathematics. In the same spirit, the research further recommends that past history and experiences towards mathematics performance should not actually be an impediment for their success in mathematics, it should actually be a yardstick for them to stay grounded and perform well in the subject letter in life. There is yet another theory that many students seem to condone to that has mashed their perceptions and attitude towards mathematics, that higher ability in mathematics coincides with the general levels of student's intelligence. The results of the study rather indicated that, that is a wrong take and a serious challenge to not only mathematics as a subject but rather to the entire academic and educational arena.

\subsection{Implications}

It therefore recommends that learners should not ground themselves in myths and baseless beliefs that if not well addressed can easily affect the student's performance in mathematics as well as making them insignificant in the society later in life. Learners must be made to look at mathematics as something that is not a fixed quantity; 
they should be made to believe that mathematics abilities are inherent in all human beings it's the degree of efforts that they take in that brings the difference in its general performance. Teachers should develop confidence in students as far as mathematics performance is concerned and revise the most favorable ways in which to facilitate learning such that students develop the love for the subject in the same way they do to other could be favored subjects. The study further implies that students need to develop confidence among them, selves take the initiatives to read and practice more in mathematics, it's about the effort one puts in, no matter the gender, age among others, if one puts in the energy and reads, many times mathematics becomes a walk over.

\section{References}

Anthony, G., \& Walshaw, M. (2009). Characteristics of effective teaching of mathematics: A view from the west. Journal of Mathematics Education, 2(2), 147-164.

Anthony, G., \& Walshaw, M. (2009). Effective pedagogy in mathematics. Brussels: The International Academy of Education.

Barton, A. C. (2000). Crafting multicultural science education with pre-service teachers through service-learning. Journal of Curriculum Studies, 32(6), 797-820. https://doi.org/10.1080/00220270050167189

Coleman, J. S., Campbell, E. Q., Hobson, C. J., McPartland, J., Mood, A. M., Weinfeld, F. D., \& York, R. L. (1966). Equality of educational opportunity. Washington, DC: US Government Printing Office.

Creemers, B. (1994). The effective classroom. London: Cassel.

Creemers, B., \& Kyriakides, L. (2008). The dynamics of educational effectiveness: A contribution to policy, practice and theory in contemporary schools. London: Routledge.

Eraikhuemen, L. (2003). The influence of gender and school location on students' academic achievement in senior secondary school mathematics. IFE Journal of Theory and Research in Education, 7(2), 99-112.

Ernest, P. (1995). Values, gender and images of mathematics: A philosophical perspective. International Journal of Mathematics Education, Science and Technology, 26(3), 449-462. https://doi.org/10.1080/0020739950260313

Forgazs, H., \& Murimo, A. E. (2011). Depictions of Females and Males in Mozambican and Victorian (Australia) Primary Mathematics Textbooks. Pythagoras, 66, 85-96.

Furinghetti, F., \& Pehkonen, E. (2002). Rethinking characterizations of beliefs. In: G. C. Leder, E. Pehkonen, \& G. Toerner (Eds.), Beliefs: A Hidden Variable in Mathematics Education? (pp. 39-58). Dordrecht: Kluwer Academic Publishers.

Gadanidis, G. (2012). Why can't I be a mathematician? FLM Publishing Association: New Brunswick.

Hannula, M. S. (2007). The effect of achievement, gender and classroom contexts on upper secondary students' mathematical beliefs. Lyon France.

Hoang, T. N. (2008). The effects of grade level, gender, and ethnicity on attitude and learning environment in mathematics in high school. International Electronic Journal of Mathematics Education, 3(1), 47-59.

Ignacio, N. G., Nieto, L. J. B., \& Barona, E. G. (2006). The affective domain in mathematics learning. International Electronic Journal of Mathematics Education, 1(1), 16-32.

Isiksal, M., \& Cakiroghi, E. (2010). Gender differences regarding mathematics achievement: The case of Turkish Middle school students. School Science and Mathematics, 108(3), 113-120. https://doi.org/10.1111/j.1949-8594.2008.tb17814.x

Kislenko, K., Breiteig, T., \& Grevholm, B. (2005). Beliefs and attitudes in mathematics teaching and learning. Trondheim: Nasjonalt Senter for Matematikk i Opplæringen.

Kleinfeld, J. (2006). Five powerful strategies for connecting boys to school. Pare presented at the White House Conference on Helping America's Youth. Indianapolis, Indiana.

Leder, G. C., \& Forgasz, H. J. (2002). Measuring Mathematical Beliefs and Their Impact on the Learning of Mathematics. Dordrecht: Kluwer Academic Publishers.

Marissa, R. (2009). Current issues and perspectives on second language learning of science. Studies in Science Education, 35(1), 93-122.

Martinot, D., \& Désert, M. (2007). Awareness of a gender stereotype, personal beliefs and self-perceptions 
Examining the influence of student's perception on mathematics performance: Case of three Rwandan schools

regarding math ability: When boys do not surpass girls. Social Psychology of Education, 10, 455-471. https://doi.org/10.1007/s11218-007-9028-9

McLeod, D. B. (1992). Research on affect in mathematics education: A conceptualization. New York: Macmillan. Mohamed, L., \& Waheed, H. (2011). Secondary students' attitude towards mathematics in a selected school of Maldives. International Journal of Humanities and Social Science, 1(15), 277-281.

Moscucci, M. (2008). About mathematical belief systems awareness. Working Group, 2, 298-307.

Mtetwa, D., \& Garofalo, J. (1989). Beliefs about mathematics: An overlooked aspect of student difficulties. Academic Therapy, 24(5), 611-618. https://doi.org/10.1177/105345128902400511

Nordin, A. B. (2005). Students' perception on teaching and learning mathematics in English. Current Issues in Language Planning, 11(4).

Pehkonen, E., \& Pietilä, A. (2003). On relationships between beliefs and knowledge in mathematics education. Paper presented at the CERME 3: Third conference of the European society for research in mathematics education, Bellaria, Italy.

Philipp, R. A. (2006). Mathematics teachers' beliefs and affect. Teachers and teaching, 7, 257-315.

Rensaa, R. J. (2006). The image of a mathematician. Philosophy of Mathematics Education Journal, $19,118$.

Renzi, L. (2005). The influence of teachers' beliefs on literature instruction in the high school English classroom (Unpublished dissertation). Ohio State University.

Rumberger, R. W., \& Palardy, .G. J. (2004). Multilevel models for school effectiveness research. In D Kaplan (Ed.), Handbook of quantitative methodology for the social sciences (pp. 241-248), https://doi.org/10.4135/9781412986311.n13

Scheerens, J., \& Bosker, R. (1997). The foundations of educational effectiveness. International Research and Pedagogy, 34(2), 93-107.

Thompson, A. G. (1992). Teachers' beliefs and conceptions: a synthesis of the research. New York: Macmillan.

Tobias, S. (2003). Overcoming math anxiety. New York: W. W. Norton \& Company.

Van Damme, J., De Fraine, B., Opdenakker, M.C., Van Landeghem, G., \& Onghena, P. (2000). Effects of schools and classes upon mathematics and language achievement: the importance of group composition. Paper presented at the European Conference on Educational Research, Edinburgh. Retrieved from http://www.leeds.ac.uk/educol/documents/00001693.htm

Van Landeghem, G., De Fraine, B., \& Van Damme, J. (2005). The consequence of ignoring a level of nesting in multilevel analysis: A comment. Multivariate Behavioral Research, 40(4), 423-434. https://doi.org/10.1207/s15327906mbr4004_2

Yin, R. K. (2003). Case study research: Design and methods. Sage: Thousand Oaks, CA. 
Kabeera, P. 